\title{
Building Worldviews With Credition Teaching Model in High School Curricula of Religious Education: A Controlled Experimental Study
}

\author{
Vasiliki Mitropouloua, Dimitra Gkirloub ${ }^{b}$ Maria Mekec
}

\begin{abstract}
This paper is the first attempt to present the results form a pilot experimental research the authors conducted with high school students to examine their worldviews with regard to the implementation of the "credition" model in Religious Education. It was implemented in the 2 nd grade of high school in selected topics. The research was held in the lessons of Religious Education during the whole school year. The authors examined the impact of the model on the students' worldviews when it is integrated with a worksheet, which was used as questionnaire (research tool). The topics to work with were selected from the expected learning results of the new aurricula for Religious Education. The experimental research was qualitative semi-structured interview and aimed to examine, when the teacher implemented the "credition" model into her teaching, how this influenced the students and helped them realize their emotions, their strength and how they subsequently changed their attitudes and life choices and future orientation. The teaching with the model was implemented in the students of two different classrooms, one who had received explanations and guidelines beforehand and the other who had not received any explanation. The results showed that the students of the classroom who had received explanations realized better their emotions than the students of the other classroom who had not. The results were encouraging to make the authors repeat the research again this year to the 3rd grade students and proceed to the forming of a teaching model for working with the model in Religious Education.
\end{abstract}

\section{Keywords}

Credition model, worldviews, religion course, teaching model, believing

Very often, we hear people use the phrase "I believe that..." when they provide argumentation on their wordviews or decisions. Yet, how many of them realize the power this verb includes/contains and the close connection it has with their emotions? And that their beliefs and argumentation, based on facts or ideas, establish connections with emotions? Do they realize that their decisions and worldviews are closely influenced by their emotions and at what grade? Had they been aw are that this influence would change/alter the ranking of their initial argumentation and subsequently their decisions and worldviews? It was supported that the "process of believing" might

\footnotetext{
aAristotle University of Thessaloniki, Greece

bMinistry of Education, Greece

cEuropean College of Sports and Exercise Physicians (E.C.O.S.E.P.)/Hellenic Federation of Mountaineering and Climbing/Hellenic Winter Sports Federetion, Greece

Correspondent Author:

Vasiliki Mitropoulou, School of Theology, Aristotle University Thessaloniki, University Campus, 54124 Thessaloniki, Greece
} 
appear in a religious or secular manner (Angel 2011). The involvement of belief in religion ignited a debate in the field of neuroscience with regard to the manifestation of religious experience in the human brain (Runehov 2007) specifically at certain areas of the neocortex. This raised the query whether the nature of religious experience is cognitive rather than emotional (Azari et al. 2001).

This issue set by the model of credition prompted the authors to apply it at high school students within a defined set of communications in the Religion course provided to them via a worksheet. The authors expected that this would help them understand better the processes of believing and their influence on the students' arguments and decisions. Additionally, the authors would trace the students' awareness on their emotions and the influence these had on their worldviews.

\section{RELIGIOUS EDUCATION IN GREECE}

The Religion course in Greece is one of the compulsory courses in Primary and Secondary Education Level (High School and Lykeion). It is taught as from the 3rd grade of Primary School to the last grade of Lyceum, that is, 10 years (out of 12 in total). It is taught for two hours per week (apart the last grade of Lyceum, when it is taught for one hour per week).

The new curricula for RE (Religious Education) emphasize the experiential/empirical and the inquiry teaching methods that promote dialogue, active cooperation among pupils and the participation of the pupils in empirical actions and group activities (Government Gazette 2017a; 2017b).

Among the aims of the new curricula 2017, the teaching of RE in schools includes (Government Gazette 2017a):

(1) Understanding of Christian faith as a means of giving sense to the world and life;

(2) Critical elaboration of religious beliefs and values;
(3) Evaluation of Christianity as a factor for the improvement of human life;

(4) Understanding of religion as a factor of development of the civilization;

(5) Development of religious conscience;

(6) Providing of chances for questioning and thinking;

(7) Knowledge of the existence of different expressions of religiosity;

(8) Facing of modern social issues;

(9) Development of independent thought and free expression.

Furthermore, the goals and aims for high school, emphasize that Religion should be a "significant factor to bring together people with different views, collaborating in critical understanding, respect and dialogue" (Government Gazette 2017a; 2017b). These are essential for the instruction of Religion in Greek schools (Government Gazette 2017a; 2017b).

\section{THEORETICAL FRAMEWORK: THE MODEL OF CREDITION}

"Credition" is a neologism which was created with the joint of two words, the latin verb "credere" (belief) and the noun "cognition" (credere + cognition = credition). The origin of the "credition" model was the "process of believing" perceived within either a religious or a secular context (Angel 2011). According to the model of credition, the processes of believing (Angel 2011) involve establishing new connections between old facts or ideas (Boyer 2003a) which influence and guide our actions and attitudes. The centre of the credition model focuses on the process character, i.e., what happens in the brain during the belief process, i.e., that it reflects on the acceptance of the pluralistic contexts of reasoning and the open exchange of ideas (Davies 2003: 238).

The brain involvement in the model of credition initiated a dialogue between various sciences as to what would be the manifestation of religious 
experience in the human brain (Runehov 2007). Neuroscience and cognitive science see it as a by-product of human cognition (Boyer 2003b). According to neuroscientific experiments (Azari et al. 2001), religious experience may be a cognitive process because certain areas of the neocortex (i.e., dorsolateral prefrontal cortex, dorsolateral frontal cortex, and medial parietal cortex) showed an activity when religious experience was involved (Azari et al. 2001) (the same cortex areas are important for the reflexive evaluation of thought) (Niendam et al. 2012). Further experiments showed that neural networks engage both in cognition and emotion but differently (Azari, Missimer, and Seitz 2005; Azari et al. 2001: 1649). Would then religious experience be cognitive process or emotional in nature or both?

The credition model supports that creditions are connected with emotions and cognitions in perfect equilibrium. Thus, creditions are considered as cognitive processes, although all belief processes do not become conscious (Angel 2011) (see Figure 1).

According to Angel (2015), the believing processes are interrelated with both cognition and emotion (Angel 2015) and include and operate on different mental operations: (1) four mental functions; and (2) basic units which are called "babs" (see B in Figure 1). The "babs" represent pieces of knowledge with emotional loadings which are assembled into coherent knowledge that constructs the so-called stabilized "bab-configurations". The "bab" can be assigned to four characteristics: (1) the propositional content; (2) the emotional moment; (3) the sense of mightiness; and (4) the sense of certainty (Angel and Seitz 2016: 7).

The four mental functions of the believing process supported by the credition model are (Sugiura, Seitz, and Angel 2015): (1) enclosure-function; converter-function; (3) stabilizer-function; and (4) modulator-function. The "enclosure function" integrates different "babs" into a new larger "bab" and then affects the larger "babs" and, subsequently, behavior and worldviews. The "converter function" denotes the close relationship between a specific belief and specific behavior or worldview. The "stabilizer function" stabilizes the belief despite the functioning of the enclosure function in a changing environment. The "modulator function" reveals the influence of the emotion state (either conscious or unconscious) (Sugiura et al. 2015) (see Figure 2).

\section{RESEARCH QUESTIONS}

The main scope and research question of the study was whether the 2 nd grade high school adolescents, at the mean age of 14 years old, are conscious of their emotions that are possibly related with their views/arguments. Consequently, if they realize the effect of their emotional experience on their decisions, how they may critically manage their cognitive and corresponding emotional mind processes. The above question, based on the credition model, was developed in accordance with one of the main teaching aims of the Religion course in Greek schools related with students' worldviews shaping and life attitudes in the modern demanding environment.

A relative teaching process and a worksheet, developed and evaluated with the view to integrate the model of credition, also gave the authors the opportunity to assess the quality of the class instructions provided, the structure, effectiveness and content of the teaching model and teaching aids used. Focusing on the experimental group of students, it was investigated how the proposed credition teaching model helped them realize their feelings related to their argumentations and possibly affected their initial thoughts/arguments on the specific topic.

\section{STUDY DESIGN}

The credition model was integrated into the teaching process by developing a worksheet, which was used as the main research tool. The whole experimental 


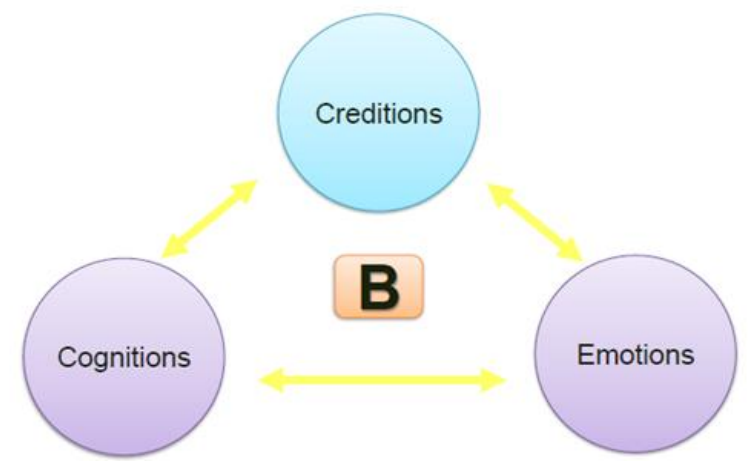

Figure 1. Creditions, Emotions, and Cognitions Are Connected in Equilibrium (Angel 2011).

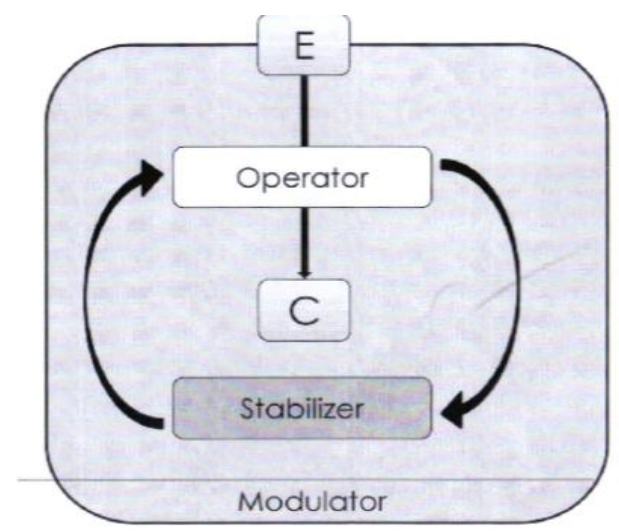

Figure 2. The Mental Functions of the Believing Process as Supported by the Credition Model (Sugiura et al. 2015).

process took place in the fields of a teaching topic instructed in the 2nd grade high school curricula of Religious Education in Greece. Teaching with the model was implemented in the students of two different classrooms for four teaching hours in school-year 2017-2018.

The first teaching hour (45 minutes) was dedicated to providing explanations on the credition model to the students of both classrooms (CRP and OCRP). However, the experimental group of children (CRP) received detailed explanations on the credition model with the view to realize the value of their emotions. They were encouraged to think how emotions probably contribute to change behavior while trying to be conscious of this emotional and cognitive process.

During the second teaching hour (45 minutes), the teacher taught both groups of students (CRP and OCRP) the topic "Jesus as a point of contradiction" using the text Lk 2, 21-35 and discussing on people's views regarding Jesus Christ. The worksheet was given in the beginning of the third teaching hour and filled in by all students in both classrooms. Mean completion was approximately estimated at 20-25 minutes. During the fourth teaching hour, the two groups (CRP and OCRP) worked together with the "bowl" teaching technique and expressed their thoughts on a related topic.

\section{PARTICIPANTS}

Aiming at the implementation of the credition model in Religious Education instruction process, relative 
Table 1. Class/Group and Gender Crosstabulation

\begin{tabular}{|c|c|c|c|c|c|}
\hline & & & & ader & Totol \\
\hline & & & Female & Male & Told \\
\hline & & Count & $13 a$ & $7 \mathrm{a}$ & 20 \\
\hline & CRP group & $\%$ within gender & $48.1 \%$ & $53.8 \%$ & $50.0 \%$ \\
\hline Classroom & & $\%$ of total & $32.5 \%$ & $17.5 \%$ & $50.0 \%$ \\
\hline /group & & Count & $14 \mathrm{a}$ & $6 a$ & 20 \\
\hline & OCRP group & $\%$ within gender & $51.9 \%$ & $46.2 \%$ & $50.0 \%$ \\
\hline & & $\%$ of total & $35.0 \%$ & $15.0 \%$ & $50.0 \%$ \\
\hline & & Count & 27 & 13 & 40 \\
\hline Total & & $\%$ within gender & $100.0 \%$ & $100.0 \%$ & $100.0 \%$ \\
\hline & & $\%$ of total & $67.5 \%$ & $32.5 \%$ & $100.0 \%$ \\
\hline
\end{tabular}

Note: Each subscript letter denotes a subset of gender categories whose column proportions do not differ significantly from each other at the .05 level.

experimental procedures were developed with high school students' involvement. All 40 participants were 14-year-old students of the 2 nd grade at the same high school in Greece, divided equally in two classrooms (20 students each). Each classroom represented a different group where the experimental classroom/group implemented the whole experimental credition teaching model process and the control classroom/group part of it. Gender proportions were not signific antly different between the experimental and the control classroom at the .05 significance level (see Table 1).

Sampling was based on a cohort study design by following two different classrooms over time while the experimental credition teaching model process $w$ as developed. The same Religious Education teacher was giving the study instructions in both experimental and control classrooms.

\section{RESEARCH TOOL}

A specially developed worksheet was used as the primary research tool. The aim was to create a worksheet (as a tool) to be used in classrooms as part of the students' activities, during the RE teaching process. It is expected to help the authors trace the students' worldviews on a specific (religious) topic when the teacher implements the credition model into the teaching process.

The worksheet developed consisted of three main parts.

The first part (part A) contained a statement/position (clum) related to the teaching topic having been selected in advance, common for both classrooms (CRP and OCRP). All students should initially decide if they agree (accept) or disagree (reject) with the clum. This was: "The Holy Spirit reveals that Jesus is the Messiah" (Lk 2, 26-27). Following the first "acceptance" question of the statement, all students had to state up to three views/argumentations in an ascending order.

The worksheet for the experimental classroom included two more parts B and C. In part B, the students were asked to think of three emotions related/corresponding to their three views/arguments stated in part A and write them down in the same ascending order. Afterwards, they were asked to think upon these emotions, try to figure out which of them would be the strongest one and/or the weakest. In the third part of the worksheet (part C), they were motivated to check upon their initial argumentations taking into consideration the emotions related to them and decide whether they would change their order. 


\section{STATISTICAL ANALYSIS}

Both qualitative and quantitative analys is were used (Javeau 2000; Robson 2002). Descriptive statistical analys is was used to calculate and to present basic characteristics of the samples as well to describe the answers given in the worksheet used as the basic research tool (Cohen, Manion, and Morrison 2001).

All arguments given by the students on the worksheet's statement were categorized according to content analysis as arguments based on class instructions, arguments based on personal view/stance, and arguments irrelevant from the topic. Emotions stated by the children in the experimental classroom were categorized according to basic and primary emotions classifications/groups (Parrott 2001; Plutchik 2001). Further classification was performed on emotions based on positive and negative emotions' classifications (Robinson 2009). Chi-square test was applied to identify significant relations/differences between categorical variables. Monte Carlo simulation was used when possible, given the small size of the current cohort sample (a classroom of 20 children in the experimental group). The confidence level of $95 \%$ was set in all statistical tests performed. SPSS version 25 and Microsoft excel 365 spreadsheets were used for the data analysis.

\section{RESULTS}

There was no statistically significant difference between the experimental (CRP) and the control (OCRP) group of students (classrooms) regarding the acceptance of the worksheet statement "The Holy Spirit reveals that Jesus is the Messiah" $\left(\mathrm{x}^{2}=2.500, \mathrm{df}\right.$ $=1, p=.114)$. Specifically, 18 out of $20(90 \%)$ students in the CRP classroom and 14 out of $20(70 \%)$ students in the OCRP classroom accepted the clum respectively (see Figure 3).

The arguments given in the case of the worksheet statement "The Holy Spirit reveals that Jesus is the
Messiah" were mostly based on class/topic instructions for both the experimental and control classrooms in general. A marginally significant difference between the two groups of students was found in the second argument given in the ascending order of the worksheet. The experimental classroom's arguments were based significantly more on class instructions and significantly less on personal view/stance $\left(\mathrm{x}^{2}=5.633, \mathrm{df}=2, p=.060\right)$. Additionally, it was observed that in all three arguments given, the experimental classroom was rated lower on expressing a personal view/stance and higher on following class instructions than the control classroom (see Figure 4). It was also noticed that the percentage of irrelevant arguments was higher in the case of the third argument asked to be written down in the ascending order in both groups of students (40\% and $50 \%$ of the arguments given as third).

The students in the experimental classroom expressed a higher percentage of joy/happiness at $27 \%$ (16 times), surprise at 23\% (14 times), and fear at 22\% (13 times), as a total of the three emotions that have written down in the ascending order of the worksheet. Less expressed emotions were disgust at $10 \%$ (six times), anticipation at $7 \%$ (four times), trust at $5 \%$ (three times), sadness and anger at 3\% each (two times each) (see Figure 5).

As regards the experimental classroom, nine out of 20 students (45\%) reviewed the order of their arguments given on the worksheet statement (clum) "The Holy Spirit reveals that Jesus is the Messiah" (see Figure 6).

It was found that most of the children having reviewed the ascending order of their arguments expressed a negative first and second emotion at a percentage of $71.4 \%$ and $60 \%$ respectively. Conversely, most of the children who did not reorder their arguments expressed a positive first and second emotion at a percentage of $69.2 \%$ and $60 \%$ respectively. The third emotion is negative for the major ity of the children (11 out of 20) (see Table 2). 


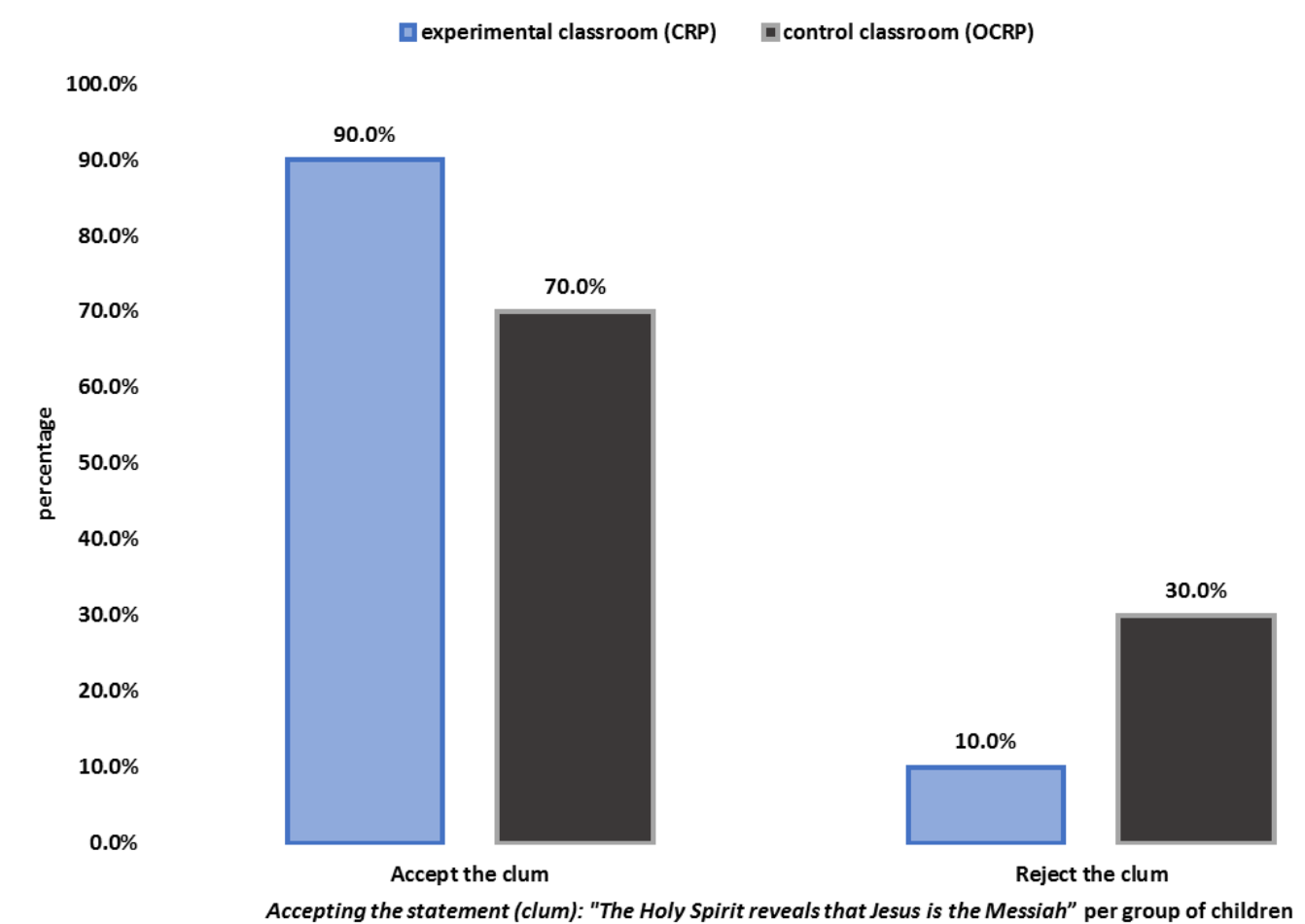

Figure 3. Acceptance of the Statement (Clum) "The Holy Spirit Reveals That Jesus Is the Messiah" per Group of Students.

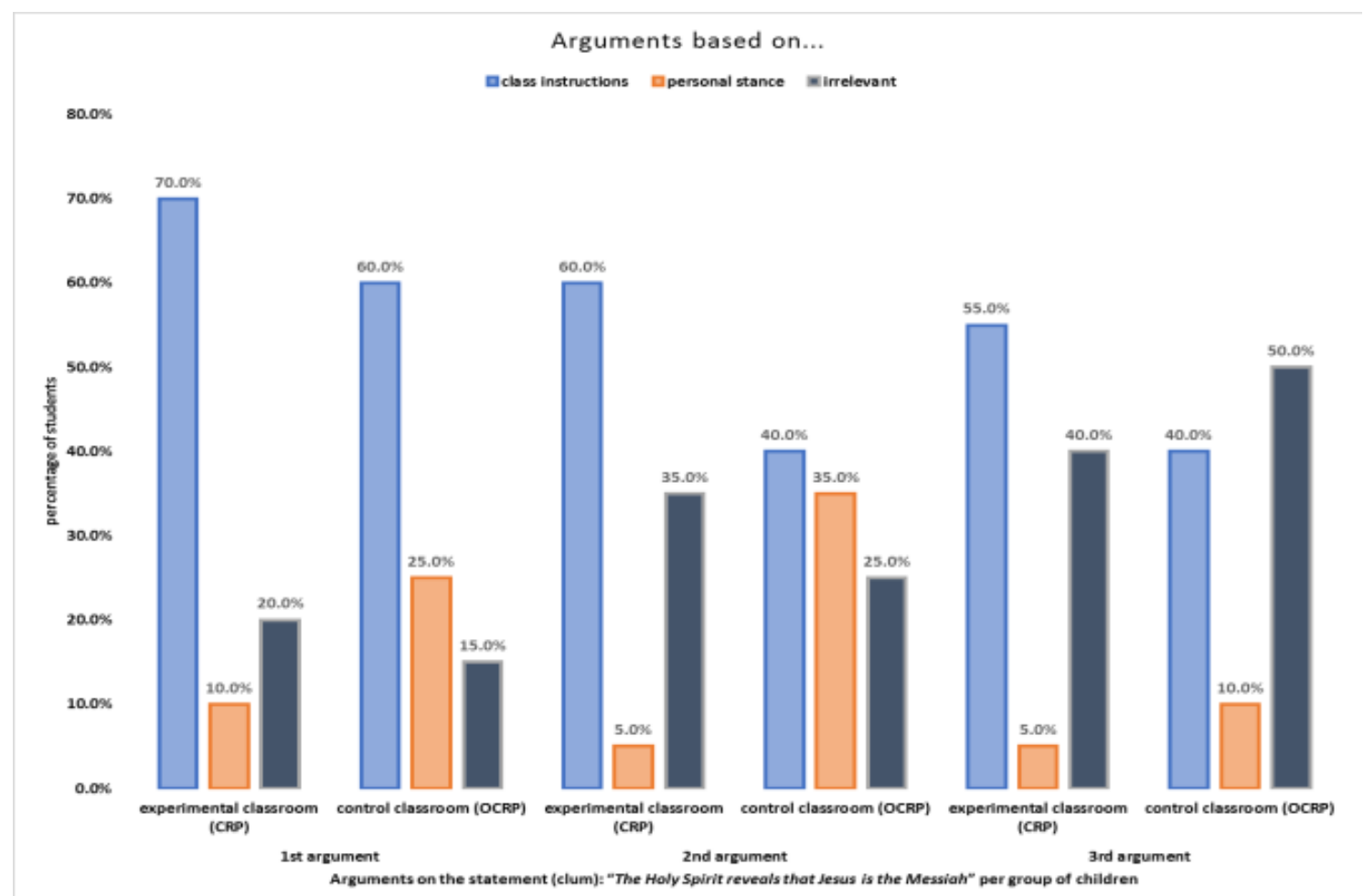

Figure 4. Arguments' Content Categories on the Statement (Clum) "The Holy Spirit Reveals That Jesus Is the Messiah" per Group of Students. 


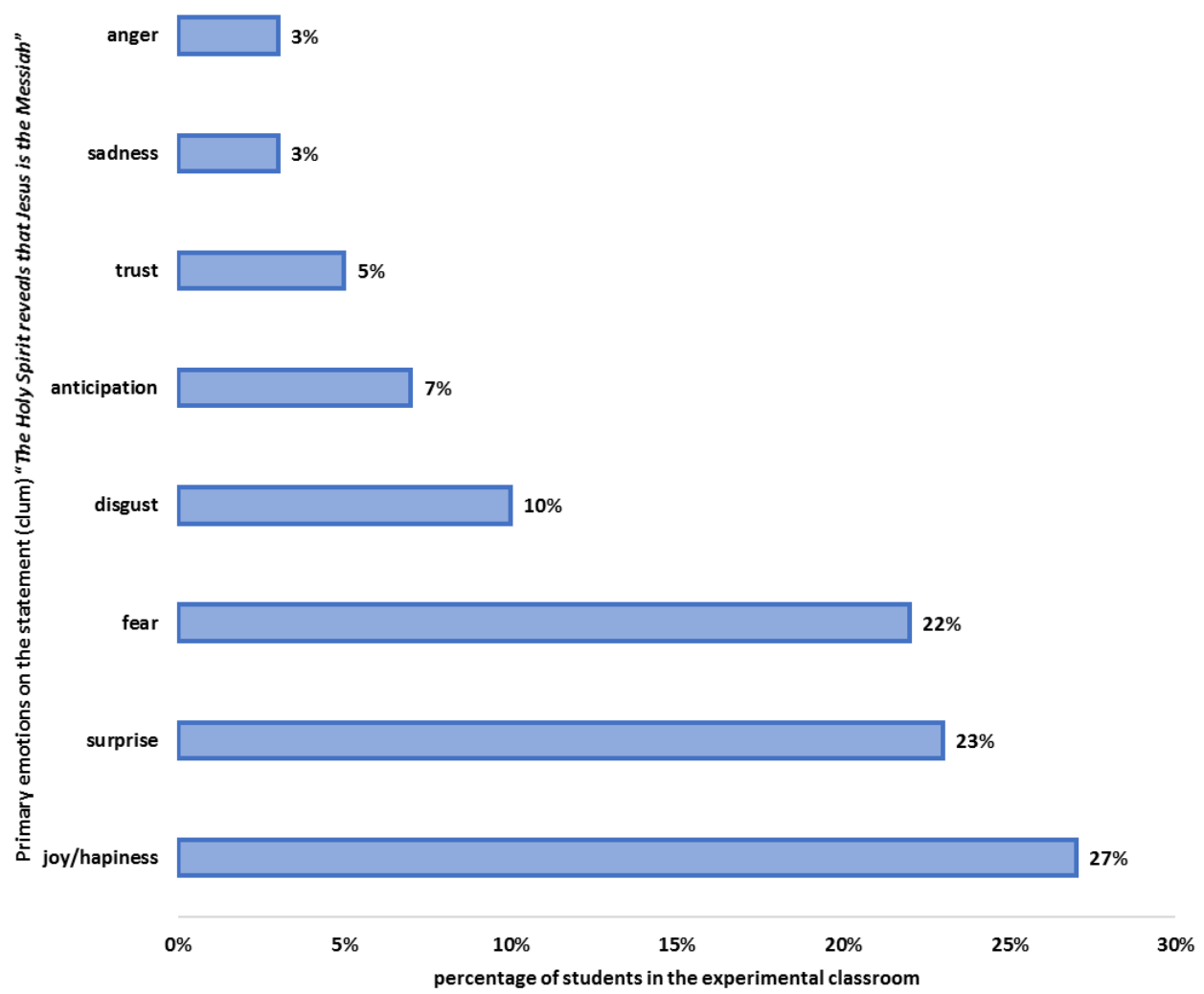

Figure 5. Primary Emotions on the Statement (Clum) "The Holy Spirit Reveals That Jesus Is the Messiah" in the Experimental Group of Students.

"The Holy Spirit reveals that Jesus is the Messiah"

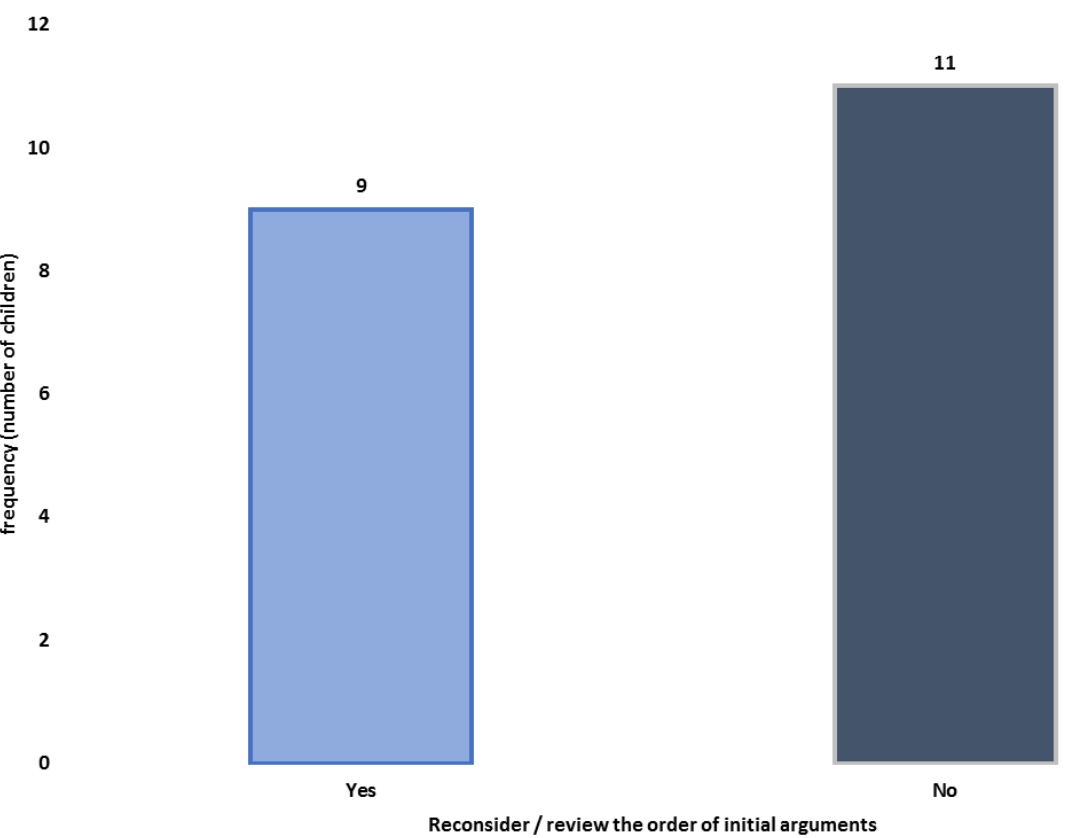

Figure 6. Number of Children Having Reviewed the Order of Their Arguments Given on Worksheet Statement (Clum). 
Table 2. Review Arguments' Order and Emotions Classification Crosstabulation

\begin{tabular}{|c|c|c|c|c|c|c|c|c|c|}
\hline & & & \multicolumn{2}{|c|}{ 1st emotion category } & \multicolumn{2}{|c|}{ 2nd emotion category } & \multicolumn{2}{|c|}{ 3rd emotion category } & \multirow[b]{2}{*}{ Total } \\
\hline & & & $\begin{array}{l}\text { Positive } \\
\text { emotions }\end{array}$ & $\begin{array}{l}\text { Negative } \\
\text { emotions }\end{array}$ & $\begin{array}{l}\text { Positive } \\
\text { emotions }\end{array}$ & $\begin{array}{l}\text { Negative } \\
\text { emotions }\end{array}$ & $\begin{array}{l}\text { Positive } \\
\text { emotions }\end{array}$ & $\begin{array}{l}\text { Negative } \\
\text { emotions }\end{array}$ & \\
\hline \multirow{6}{*}{$\begin{array}{l}\text { Review } \\
\text { arguments' } \\
\text { order }\end{array}$} & \multirow{4}{*}{ Yes } & Count & $4 \mathrm{a}$ & $5 \mathrm{a}$ & $6 a$ & $3 a$ & $5 \mathrm{a}$ & $4 \mathrm{a}$ & 9 \\
\hline & & $\begin{array}{l}\% \text { within } 1 \text { st } \\
\text { emotion }\end{array}$ & $30.8 \%$ & $71.4 \%$ & $40.0 \%$ & $60.0 \%$ & $55.6 \%$ & $36.4 \%$ & $45.0 \%$ \\
\hline & & $\%$ of total & $20.0 \%$ & $25.0 \%$ & $30.0 \%$ & $15.0 \%$ & $25.0 \%$ & $20.0 \%$ & $45.0 \%$ \\
\hline & & Count & $9 \mathrm{a}$ & $2 \mathrm{a}$ & $9 \mathrm{a}$ & $2 \mathrm{a}$ & $4 \mathrm{a}$ & $7 \mathrm{a}$ & 11 \\
\hline & \multirow[t]{3}{*}{ No } & $\begin{array}{l}\text { \% within } 1 \text { st } \\
\text { emotion }\end{array}$ & $69.2 \%$ & $28.6 \%$ & $60.0 \%$ & $40.0 \%$ & $44.4 \%$ & $63.6 \%$ & $55.0 \%$ \\
\hline & & $\%$ of total & $45.0 \%$ & $10.0 \%$ & $45.0 \%$ & $10.0 \%$ & $20.0 \%$ & $35.0 \%$ & $55.0 \%$ \\
\hline \multirow{3}{*}{ Total } & & Count & 13 & 7 & 15 & 5 & 9 & 11 & 20 \\
\hline & & $\begin{array}{l}\% \text { within } 1 \text { st } \\
\text { emotion }\end{array}$ & $100.0 \%$ & $100.0 \%$ & $100.0 \%$ & $100.0 \%$ & $100.0 \%$ & $100.0 \%$ & $100.0 \%$ \\
\hline & & $\%$ of total & $65.0 \%$ & $35.0 \%$ & $75.0 \%$ & $25.0 \%$ & $45.0 \%$ & $55.0 \%$ & $100.0 \%$ \\
\hline
\end{tabular}

Note: Each subscript letter denotes a subset of emotion category whose column proportions do not differ significantly from each other at the .05 level.

\section{CONCLUSIONS}

The answers of the students' group that had received detailed explanations beforehand (CRP), showed that these students were more mature and more conscious on their emotions. They expressed deeper and more thoughtful views/argumentations than the group of students that had not received any explanations (Paloutzian and Mukai 2017). The answers of the CRP group showed that when they became conscious of their emotions, they realized that their initial views were too hard or emotionless and that their attitudes should be more flexible and filled with empathy (Davies 2017). Furthermore, the students of the control group (CRP) criticized the lack of emotions in the answers of the OCRP students' group.

It was observed that a bigger proportion of students (90\%) in the experimental classroom accepted the given statement than in the control classroom (70\%), probably trying to follow the more analytical class instructions given to them. On the other hand, this proportion, of the acceptance of the worksheet statement, was not significantly different $(\alpha=.05)$.

Regarding the content classification of the three arguments given by both groups of students in an ascending order, the experimental classroom $\mathrm{w}$ as rated lower on expressing a personal view/stance and higher on following class instructions than the control classroom. This different cognition was marginally in the case of the second argument given in the ascending order on the worksheet's statement $\left(\mathrm{x}^{2}=\right.$ $5.633, \mathrm{df}=2, p=.060$ ).

Basic/primary emotions related with the experimental group of students' arguments appearing more as a total were: joy/happiness (27\%), surprise $(23 \%)$, and fear (22\%) (Plutchik 2001).

Almost half of the children $(45 \%)$ in the experimental classroom reordered the arguments given on the worksheet statement. At the same time, most of the children reordering their arguments expressed a negative first and second emotion (71.4\% and 60\% respectively) while most of the children not reordering their arguments expressed a positive first and second emotion at a percentage of $69.2 \%$ and $60 \%$ respectively.

In the case of the third argument and the third corresponding emotion, there were the highest percentages of irrelevant arguments (40\% for the experimental and $50 \%$ for the control group) and negative emotions (11 out of 20 students for the experimental group). 


\section{LIMITATIONS AND FUTURE IMPLICATIONS}

The results were encouraging to make the authors extent the research on a prototype credition teaching model. There was a need though to take into consideration different topics except RE as well as more general educational-learning and teaching targets.

The size of the sample was small due to the difficulty to introduce a teaching model in the school curricula and support the experimental profound analys is of a credition teaching model in adolescents. Control classroom was included upon the first stage of the experimental cohort in order to test the quality and the suitability of the teaching techniques and instructions, as well as the structure, the content, and the effectiveness of the teaching model and the teaching aids used.

The results showed some improvements needed to be implemented on the teaching model, e.g., the instructions to be more detailed especially as concerns the emotions. Additionally, the students need more clarifications as to how to learn to separate the basic-primary emotions from feelings and from secondary emotions and thoughts.

The ages of the sample were 14-year-old adolescents who are forming their self-image and self-consciousness. They get bored very easy and they overestimate the capabilities of their minds to think of new situations and form new worldviews. Their need for friends makes them want close relations with friends and this requires the use of more cooperative teaching methods and digital interactive material and medium. To make them concentrate better and deeper, they need shorter analysis or more attractive material.

The authors need to extent the analysis on the "bowl" teaching technique, and the qualitative analysis, as well as the feedback material in order to improve the integration of the credition model as a teaching and research tool (e.g. the worksheet used).
Currently, the critical elaboration in the fields of cognitive and emotional mind processes and interactions was achieved by implementing the model of credition in RE. It is in the authors' future plans to extend its implementation into other courses.

\section{References}

Angel, H.-F. 2011. "Can the Concept of Creditions Be Applicable to Psychology of Religion?" Presented at the IAPR Congress 2009, 23-27 August, Vienna, Austria.

—. 2015. "No Believing Without Emotion. The Overlapping of Emotion and Cognition." Studies in Science and Theology 15:215-222.

Angel, H.-F. and R. J. Seitz. 2016. "Process of Believing as Fundamental Brain Function: The Concept of Credition." Forschungsbulletin 3(1):1-20.

Angel, H.-F., L. Oviedo, R. Paloutzian, A. Runehov, and R. J. Seitz., eds. 2017. Processes of Believing: The Acquisition, Maintenance, and Change in Creditions. Germany: Springer.

Azari, N. P., J. Missimer, and R. J. Seitz. 2005. "Religious Experience and Emotion: Evidence for Distinctive Cognitive Neural Patterns." International Journal of Psychology of Religion 15(4):263-281.

Azari, N., J. Nickel, G. Wunderlich, M. Niedeggen, H. Hefter, L. Tellmannn, ... R. Seitz. 2001. "Neural Correlates of Religious Experience." European Journal of Neuroscience 13(8):1649-1652.

Boyer, P. 2003a. "Science, Erudition and Relevant Connections." Journal of Cognition and Culture 3(4):344-358.

_ 2003b. "Religious Thought and Behavior as By-products of Brain Function." Trends in Cognitive Sciences 7(3):119-124.

Cohen, L., L. Manion, and K. Morrison. 2001. Research Methods in Education. 5th ed. Oxford: Routledge Falmer Publisher.

Davies, A. 2003. The Native Speaker: Myth and Reality. UK: Multimedia Matters Ltd.

Davies, O. 2017. "Cognition, Emotion and the Ethics of Authenticity." Pp. 277-287 in Processes of Believing: The Acquisition, Maintenance, and Change in Creditions, edited by H.-F. Angel, L. Oviedo, R. Paloutzian, A. Runehov, and R. J. Seitz. Germany: Springer.

Government Gazette. 2017a. Curricula for Religious Education in Elementary and High School. 2104/19.06.2017. Athens: National Printhouse.

- 2017b. Curricula for Religious Education in General and 
Vocational Lyceum. 2105/19.06.2018. Athens: National Printhouse.

Javeau, C. 2000. Research With Questionnaire. Athens: Typothito, Giorgos Dardanos.

Niendam, T. A., A. R. Laird, K. L. Ray, Y. M. Dean, D. C. Glahn, and C. S. Carter. 2012. "Meta-Analy tic Evidence for a Superordinate Cognitive Control Network Subserving Diverse Executive Functions." Cognitive Affective and Behavioral Neuroscience 12(2):241-268.

Palutzian, R. and K. Mukai. 2017. "Believing, Remembering and Imagining: The Roots and Fruits of Meanings Made and Remade." Pp. 39-49 in Processes of Believing: The Acquisition, Maintenance, and Change in Creditions, edited by H.-F. Angel, L. Oviedo, R. Paloutzian, A. Runehov, and R. J. Seitz. Germany: Springer.

Parrott, W. 2001. Emotions in Social Psychology (Key Readings in Social Psychology). Philadelphia: Psychology Press.

Plutchik, R. 2001. "The Nature of Emotions." American Scientist 89(4):344-350.

Robinson, C. 2009. Research in the Real World. Translated in Greek by V. Ntalakou and V. Vasilikou. Athens: Gutenberg.

Robson, C. 2002. Real World Research: A Resource for Social Scientists and Practitioner-Researchers. 2nd ed. Oxford: Blackwell.

Runehov, A. L. C. 2007. Sacred or Neutral? The Potential of Neuroscience to Explain Religious Experience. Goettingen:
Vandenhoeck and Ruprecht.

Sugiura, M., R. J. Seitz, and H.-F. Angel. 2015. "Models and Neural Bases of the Believing Process." Journal of Behavioural Brain Science 5(1):12-23.

Wortham, J. 2001. "Facebook Tops 500 Million Users." The New York Times, July 10. Retrieved September 20, 2010 (http://www.nytimes.com/2010/07/22/technology/22facebo ok.html?_r=2\&partner=rss\&emc=rss).

\section{Bios}

Vasiliki Mitropoulou, Ph.D., associate professor, Faculty of Theology, Aristotle University of Thessaloniki, Greece; research fields: education, religious education, teacher training, instruction, instructional design, ICT in education, media and religious literacy, intercultural instruction.

Dimitra Gkirlou, $\mathrm{PhD}$ candidate, high school teacher, Ministry of Education, Greece; research fields: education, religious education, instruction, instructional design in education and in religious education.

Maria Meke, $\mathrm{PhD}$ candidate, health statistics, member of European College of Sports and Exercise Physicians (E.C.O.S.E.P.), scientific consultant of Hellenic Federation of Mountaineering and Climbing and Hellenic Winter Sports Federetion, Greece; research fields: statistics, data analysis, data management, data visualization, adult education and instruction. 